\title{
Cusp resistance to fracture of posterior teeth restored with fluoride release restorative materials
}

Ammar Kh Al-Nori

BDS, MSc (Assist Lect)
Department of Prosthetic Dentistry

College of Dentistry, University of Mosul

\begin{abstract}
The aim of this study is to investigate the effect of different fluoride release restorative materials (resin modified glass ionomer, composite resin and conventional type of glass ionomer) on fracture resis-tance of the restored teeth.

Forty recently extracted human maxillary premolar teeth were used in this study. The teeth were mounted in acrylic resin inside a plastic ring by the use of a surveyor.

The specimen randomly divided into five groups: Group A: Five intact teeth; Group B: Five teeth prepared but not restored; Group C: Ten teeth restored with resin modified glass ionomer (Vitremer); Group D: Ten teeth restored with composite resin (Tetric); and Group E: Ten teeth restored with conventional type of glass ionomer (Ionofil).

Class II mesio-occluso-distal cavity preparation was made for the teeth of Groups B through E.

The specimens were thermocycled (5 ${ }^{\circ} \mathrm{C}$ to $55^{\circ} \mathrm{C}$ ) for 100 cycles, stored for one week at $37{ }^{\circ} \mathrm{C}$ in distilled water and then fractured by occlusal force.

The statistical analysis of the results showed that resin modified glass ionomer and composite resin significantly increase the resistance of prepared teeth to fracture.
\end{abstract}

Key Words: Tooth fracture, composite resin, glass ionomer.

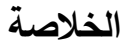

$$
\begin{aligned}
& \text { إن الغرض من هذه الدراسة هو تقويم تأثير الأنواع }
\end{aligned}
$$

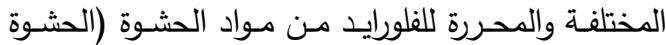

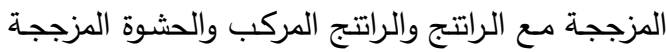

$$
\begin{aligned}
& \text { التقليدية) على مقاومة كسر إلأسنان المحشوة. }
\end{aligned}
$$

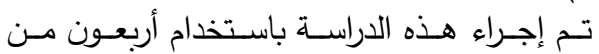

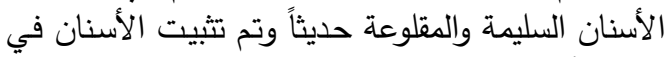

$$
\begin{aligned}
& \text { مادة الأكريلك داخل حلقة بلاستيكية وباستخدام جهاز } \\
& \text { التخطيط. }
\end{aligned}
$$

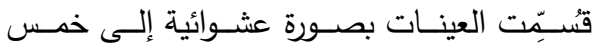

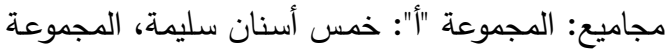

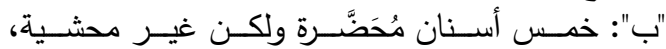

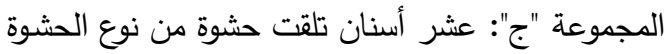

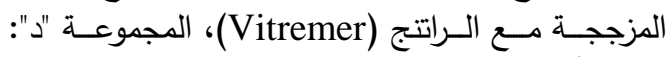

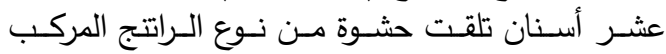

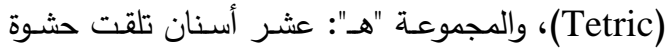

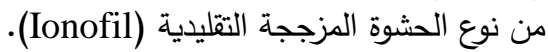

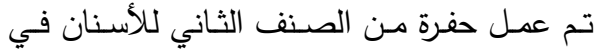

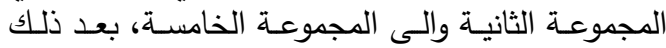

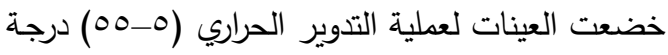

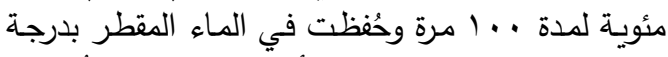

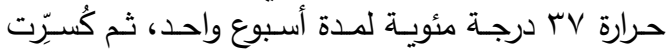

$$
\begin{aligned}
& \text { بواسطة تسليط قوة. }
\end{aligned}
$$

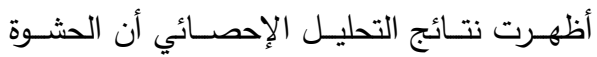

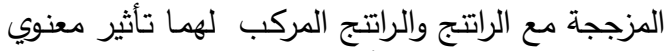

$$
\begin{aligned}
& \text { في زيادة مقاومة كسر الأسنان المُحَضَّرة. }
\end{aligned}
$$

\section{INTRODUCTION}

Any preparation appears to decrease a tooth's resistance to fracture. ${ }^{(1,2)}$ Conservative preparation design may affect fracture pattern and enhance option for subsequent restoration. ${ }^{(3)}$

Amalgam has been used to restore tooth structure for years. the mechanical, physical and biological properties of amalgam are well established, but the success of this material is largely determined by strict adherence to the proper essentials of cavity design. ${ }^{(4)}$ Large amounts of tooth preparation were required for proper retention and strength in amalgam restoration, even in teeth with minimal 
decay. More recently, a technique for bonding amalgam to tooth structure with an adhesive resin liner demonstrated strength similar to that of bonded composite resin. ${ }^{(5-7)}$ The addition of fluoride to amalgam will decrease in compressive strength of amalgam, particularly at high fluoride concentration. ${ }^{(8)}$ So introduce other materials which release fluoride like tooth coloured restorative material (composite resin and glass ionomer).

Composite resin can be used for restoration of posterior teeth only in certain conditions such as when esthetics is the primary concern of the patient, in Class I and Class II cavities that are not subjected to high stress. ${ }^{(9-11)}$

The introduction of glass ionomer cements has increased the bond strength to tooth structure by mean of chemical bonds. ${ }^{(12,13)}$

Light cured resin modified glass ionomer has recently developed in the market. It has better properties than conventional glass ionomer cement. Generally, they have the advantages of good adhesion to the tooth structure, esthetics, fluoride release and rapid hardening by visible light. ${ }^{(14,15)}$

The aim of this study is to evaluate the relative effect of different fluoride release restorative materials (resin modified glass ionomer, composite resin and conventional type of glass ionomer) on fracture resistance of posterior teeth.

\section{MATERIALS AND METHODS}

Forty maxillary premolar teeth extracted for orthodontic purposes were collected and stored in distilled water until used. The teeth were caries free. They were scaled and cleaned with non fluoridated pumice (Quayle Dental, England), then examined by fiberoptic light to exclude the cracked teeth.

Specimens were mounted in an autopolymerizing resin base. The procedure for mounting the teeth was done as follows:

A clip of flexible wire was adapted to the mesial and distal surfaces at the cementoenamel junction holding the tooth with the long axis of the tooth perpendicular to the plane of the base of surveyor
(Quayle Dental MF, England). Then the wire, with the tooth, stuck to the ring by sticky wax. A thin mix of resin was poured into the ring, embedding the root. The level of resin on the root surface was brought to cementoenamel junction. The ring was immediately placed in a distilled water to aid in dissipation of the heat of reaction generated by the setting resin.

The specimens were then randomly divided into five test groups:

Group A: Five intact teeth.

Group B: Five teeth prepared but not restored.

Group C: Ten teeth prepared and restored with resin modified glass ionomer (Vitremer; 3M, Dental Product, St Paul, MN55144).

Group D: Ten teeth prepared and restored with composite resin (Tetric; Vivadent, Schaan / Liechtenstein).

Group E: Ten teeth prepared and restored with conventional type of glass ionomer (Ionofil; Voco, 27457, Coxhaven, Germany).

Regarding cavity preparation, Class II mesio-occluso-distal (MOD) cavities were prepared in specimens of groups B through $\mathrm{E}$. The preparation were made by using parallel sided carbide fissure bur No. 014 adjusted in high speed handpiece with water coolant. The bur was replaced after each five preparations. A width of one fourth of intercuspal distance was chosen for the occlusal portion of the preparation and one third of the total bucco-lingual distance was used for the proximal boxes. The buccal and lingual walls were prepared parallel to each other. The depth of the cavity at the occlusal portion was 2 $\mathrm{mm}$. The axial wall in the proximal box was prepared to depth of $1 \mathrm{~mm}$; mesiodistal width of gingival floor was kept 2 $\mathrm{mm}$. No retentive grooves were used on the buccal and lingual proximal walls. The surveyor was used in order to standardize the cavity preparation. The ring was fixed on the platform of the surveyor previously adjusted in a parallel plane with the base, a parallel sided fissure bur was passed through the parallel walls making them parallel to each other. The width of the occlusal and proximal portions was che- 
cked using a digital vernier (Electronic digital vernier caliper, Lezaco, China).

The internal line angles of the cavity were rounded by using a round bur No. 1/4 with a conventional speed handpiece.

The teeth of group $\mathrm{C}$ were treated with Vitremer primer for 30 seconds, then air dried with oil free air for 15 seconds and light cured for 20 seconds. After that the powder and liquid of Vitremer was mixed, filled and cured for 40 seconds. The restoration was done by one step because Vitremer restorative material is a dual cure.

The enamel margins and subsequently the dentin of teeth of group D were etched with $37 \%$ phosphoric acid gel for 15 seconds, then thoroughly rinse off acid with water for 15 seconds and the tooth surface was dried with oil free air for 10 seconds. Then the teeth were treated with Syntac single component for 20 seconds, then disperse the material to a thin layer with air free of oil until movement of the liquid is no longer visible, light cured for 20 seconds, then apply Tetric composite resin and adapted carefully with plastic instrument; ASH 6 to the level of pulpal floor and light cured for 40 seconds. This procedure was repeated for the occlusal portion. A matrix was used before each polymerization. The excess materials were removed by using silicone rubber finishing bur (Translux; Trans AG, Feidweisen, CH 9450, Germany).

The teeth of group E were cleaned with 3\% hydrogen peroxide and then rinse carefully with water and dried. Ionofil powder and liquid was mixed according to the manufacturer's instructions and inserted into the cavity. Immediately upon removal of stripes, the filling has to be covered with varnish for protection from moisture. After setting after 6-7 minutes, the excess was removed with a sharp hatchet.

The specimens of five groups were thermocycled between 5 to $55 \pm 2{ }^{\circ} \mathrm{C}$ for 100 cycles and stored in distilled water for 1 week in an incubator at $37{ }^{\circ} \mathrm{C}$ before testing.

Specimens were tested for resistance to fracture with a universal compressive machine (Engineering test equipment, Model CN 472, Soil test, USA). One metal rod approximately $5.5 \mathrm{~mm}$ in diameter was used in this study. The plunger contacted only the occlusal inclines of the facial and lingual cusps and not the restoration. The specimens were tested at a cross-head speed of $0.5 \mathrm{~mm} /$ minute. The forces which were necessary to fracture the teeth were recorded.

\section{RESULTS}

Table (1) presents the mean of forces in $\mathrm{Kg}$ required to fracture the specimens of the five groups. The values of group A represent the highest while the values of group B represent the lowest.

The mean and standard deviation of the force required to fracture the specimen of group A $(150.4 \pm 16.11 \mathrm{Kg})$, group B $(47.6 \pm 5.94 \mathrm{Kg})$, group C $(80.1 \pm 11.49$ $\mathrm{Kg})$, group $\mathrm{D}(78 \pm 16.86 \mathrm{Kg})$ and group $\mathrm{E}$ $(54 \pm 10.64 \mathrm{Kg})$.

Table (1): Mean and standard deviation of tooth fracture

\begin{tabular}{ccc}
\hline Group & Treatment & Mean Force \pm SD $(\mathbf{K g})$ \\
A & Intact & $150.4 \pm 16.11$ \\
B & Prepared, Unrestored & $47.6 \pm 5.94$ \\
C & $\begin{array}{c}\text { Restored with Vitremer Resin } \\
\text { Modified Glass Ionomer }\end{array}$ & $80.1 \pm 11.49$ \\
D & Restored with Tetric Composite & $78 \pm 16.86$ \\
E & Restored with Ionofil Glass & $54 \pm 10.64$ \\
\hline
\end{tabular}

SD: Standard deviation. 
Statistical analysis of data by using analysis of variance revealed that there is significant difference $(p<0.01)$ between the five groups as shown in Table (2).

Further analysis of data was needed to examine the differences between different pairs of groups and this done by applying the student's t-test to compare between each pair of groups (Table 3). The analysis included:

Significant difference between the values of force required to fracture intact teeth (group A) and the other four groups.

Significant difference was found between the values of force required to fracture teeth restored with Vitremer (group C) and the values of teeth prepared but not restored (group B). Also a significant difference was found between the values of teeth restored with Vitremer (group C) and the values of teeth restored with Ionofil (group E).

Significant difference was found between the values of force required to fracture teeth restored with Tetric composite resin (group D) and the values of teeth prepared but not restored (group B). Also a significant difference was found between the values of force required to fracture teeth restored with Tetric composite resin (group D) and the values of teeth restored with Ionofil (group E).

No significant difference was found between the values of teeth restored with Ionofil (group E) and the values of teeth prepared but unrestored (group B).

No significant difference was found between the values of teeth restored with Vitremer (group C) and the values of teeth restored with Tetric composite (group D).

Table (2): Analysis of variance (ANOVA) of all the five groups

\begin{tabular}{ccccc}
\hline Source of Variation & SS & d.f & MS & F-value \\
\hline Between Groups & 67113.7 & 4 & 16778.4 & 70.349 \\
Within Groups & 10732.7 & 45 & 238.5 & \\
Total & 77846.4 & 49 & & \\
\hline
\end{tabular}

SS: Sum of squares.

d.f: Degree of freedom.

MS: Mean squares.

Table (3): t-test of the differences between different pairs of groups

\begin{tabular}{lc|cc}
\hline Group & $\begin{array}{c}\text { Significant Difference } \\
\text { at } \boldsymbol{p}<\mathbf{0 . 0 1}\end{array}$ & Group & $\begin{array}{c}\text { No Significant } \\
\text { Difference at } \boldsymbol{p}<\mathbf{0 . 0 1}\end{array}$ \\
\hline A \& B & $\mathrm{t}=18.749$ & $\mathbf{E}$ \& B & $\mathrm{t}=1.450$ \\
A \& C & $\mathrm{t}=10.361$ & C \& D & $\mathrm{t}=0.597$ \\
A \& D & $\mathrm{t}=11.867$ & & \\
A \& E & $\mathrm{t}=16.418$ & & \\
C \& B & $\mathrm{t}=7.401$ & & \\
C \& E & $\mathrm{t}=4.744$ & & \\
D \& B & $\mathrm{t}=5.131$ & & \\
D \& E & $\mathrm{t}=3.963$ & & \\
\hline
\end{tabular}

Group A: Intact;

Group B: Prepared, unrestored;

Group C: Restored with Vitremer resin modified glass ionomer;

Group D: Restored with Tetric composite;

Group E: Restored with Ionofil glass ionomer.

Table (4) presents the number of teeth fractured by each specific type of the fracture. Cusps of intact teeth (group A) fractured at the base of the cusp. Teeth prepared but unrestored (group B) frac- tured at the base of the cusp or split at the pulpal floor. Teeth restored with Vitremer (group C) fractured mostly in a combination type of fracture through the bulk of restoration and fracture at the tooth resto- 
ration interface. Teeth restored with Tetric composite (group D) mostly fractured at tooth restoration interface. Teeth restored with Ionofil fractured always through the bulk of the restoration.

Table (4): Modes of failure of the groups of the experiment

\begin{tabular}{lccccc}
\hline \multirow{2}{*}{ Mode of Failure } & \multicolumn{5}{c}{ Groups } \\
\cline { 2 - 6 } & A & B & C & D & E \\
\hline Adhesive Failure & & & 2 & 7 & 1 \\
$\begin{array}{l}\text { Cohesive Failure } \\
\text { Combined Adhesive / Cohesive }\end{array}$ & & & & 8 \\
$\begin{array}{l}\text { Fracture Through the Pulpal Floor } \\
\text { Fracture at the Base of Cusp }\end{array}$ & 5 & 1 & & 3 & 1 \\
\hline Gacture & 4 & 10 & 10 & 10 \\
\hline
\end{tabular}

Group A: Intact;

Group B: Prepared, unrestored;

Group C: Restored with Vitremer resin modified glass ionomer;

Group D: Restored with Tetric composite;

Group E: Restored with Ionofil glass ionomer.

\section{DISCUSSION}

In this study MOD cavity preparation was used because it causes more weakening to the tooth structure than MO or DO preparations.

The results of this study indicate that the cavity preparation reduced the strength of prepared teeth when compared with sound unprepared teeth.

In this study, different types of restorative materials produced different results. It was found that the Vitremer resin modified glass ionomer and Tetric composite resin were significantly stronger than either unrestored prepared teeth or restored with Ionofil which is a conventional type of glass ionomer.

Resin modified glass ionomer contain resin component. This modification over the conventional glass ionomer cement im-proves the adherence to enamel and dentin. ${ }^{(16,17)}$ This property strengthen the tooth-material interface and this mean it is more difficult to cause failure at toothmaterial interface. In addition to that, the resin component improves the flexural strength of glass ionomer. ${ }^{(18,19)}$ This property means more difficult to cause failure within the material, so that the resin modified glass ionomer has great potential as a cusp reinforcing material. This finding was in agreement with Marcherson and Smith. ${ }^{(20)}$

Teeth restored with Tetric composite resin significantly produce greater fracture resistance than either teeth prepared unrestored or restored with Ionofil glass ionomer. This may be due to the bonding agent used in this study that developed micromechanical retention with etched enamel. ${ }^{(21)}$ This result has come in agreement with other studies. ${ }^{(22,23)}$

In this study, teeth restored with conventional type of glass ionomer significantly need less force to fracture compared to Vitremer resin modified glass ionomer and Tetric composite, but showed no significant difference than prepared unrestored teeth. This finding has come in agreement with Chakmakchi's study. ${ }^{(23)}$ In spite of the adhesive property of glass ionomer to the tooth structure but the flexural strengths are insufficient. ${ }^{(24)}$ So, most of failure occurred within the material because the bond strength to the tooth structure exceed its cohesive strength. ${ }^{(23)}$

\section{CONCLUSIONS}

It was concluded that the sound unprepared tooth significantly stronger than the teeth restored with resin modified glass ionomer, composite resin and conventional type of glass ionomer. Also, the resin modified glass ionomer and composite resin were considered to be as a tooth reinforcing materials. 


\section{REFERENCES}

1. Cavel W, Kelsey W, Blanken R. An in vivo study of cuspal fracture. J Prosthet Dent. 1986; 53: 38-42.

2. Eakle W, Maxwell E, Braly B. Frac-tures of posterior adult teeth. J Am Dent Assoc. 1986; 112: 215218.

3. Carson G, Murchison D, Cohen R, Broom J. Resistance to fracture of tooth with various preparation for amalgam. J Dent. 1996; 24: 407410.

4. Bouschov F, Martin R. A review of concept of silver amalgam restoration. J Prosthet Dent. 1976; 36: 532-536.

5. Staninec M, Holt M. Bonding of ama-lgam to tooth structure: Tensile adhe-sion and microleakage tests. $J$ Prosthet Dent. 1988; 59: 397-402.

6. Staninec M, Eakle W, Silverstein S, Marshall G, Artiga N. Bonded amal-gam sealants: Two year clinical results. J Am Dent Assoc. 1998; 129: 323-329.

7. Eakle W, Staninec M, Yip R, Chavez M. Mechanical retention versus bon-ding amalgam and gallium alloy restor-ations. $J$ Prosthet Dent. 1994; 72: 351-354.

8. Fazzi R, Vieria D, Zucas S. Fluoride release and physical properties of a flu-oride containing amalgam. J Prosthet Dent. 1977; 38: 527-531.

9. Stampalia L, Nicholls J, Bruduick $\mathrm{J}$, Jones D. Fracture resistance of teeth filled with resin bonded restoration. J Prosthet Dent. 1986; 55: 694-698.

10. Bayne S, Heyman H, Swift E. Update on dental composite restoration. $J$ Am Dent Assoc. 1994; 125: 687-701.

11. Leinfelder $\mathrm{K}$. Using composite resin as a posterior restorative material. J Am Dent Assoc. 1991; 122: 65-68.

12. Laciefeld W, Rein D. Tensile bond strength of glass ionomer cement. $J$ Prosthet Dent. 1985; 53: 194-198.

13. Mclean J. Cermet cement. J Am Dent Assoc. 1990; 120: 43-46.
14. Levartovsky S, Georgescu N, Geold-stine G. Shear bond strength of several new core materials. $J$ Prosthet Dent. 1996; 75: 154-158.

15. Sidhn S, Watson T. Resin modified glass ionomer materials. J Dent. 1995; 8: 59-67.

16. Mjtyas M. Clinical evaluation of a resin modified glass ionomer adhesive sys-tem. Oper Dent. 1998; 23: 290-293.

17. Swift E, Pawlus M, Vargas M. Shear bond strengths of resinmodified glass ionomer restorative materials. Oper Dent. 1995; 20: 138-143.

18. Gladys S, Van-Meerbeek B, Bream M, Vanherle G Comparative physico-mechanical characterization of a new hybrid restorative materials with conventional glass ionomer and composite resin restorative materials. J Dent Res. 1997; 76: 883-894.

19. Levartovsky S, Kuyinu E, Georgescu M. A comparison of diametral tensile strength, the flexural strength and the compressive strength of two new core materials to a silver alloy reinforced glass ionomer material. J Prosthet Dent. 1994; 72: 481485.

20. Marcherson L, Smith B. Reinforcement of weakened cusps by adhesive restor-ative materials. An in vitro study. Br Dent J. 1995; 178: 341-244.

21. Al-Nasiry A. The evaluation of micro-leakage in recent posterior composite resin. MSc thesis. College of Dentistry. University of Baghdad. 2001.

22. Eakle W. Fracture resistance of teeth with class II bonded composite restor-ation. J Dent Res. 1986; 65: 149-153.

23. Chakmakchi MN. An in vitro evalu-ation of cusp resistance to fracture of posterior teeth restored with silver glass ionomer compared with composite resin system. MSc thesis. College of Dentistry. University of Baghdad. 1992. 
24. Lorente M, Godin C, Meyer J. Mech-anical behavior of glass ionomer cem-ent affected by long

Received: 9/12/2003 term storage in water. Dent Mater. 1994; 10: 37-44.

Accepted for Publication: 14/1/2004

Al-Rafidain Dent J

Vol. 3, No. 2, 2003 